\title{
Expression analysis of long non-coding RNAs in a renal ischemia-reperfusion injury model $^{1}$
}

Qiu Tao' (D), Wang Tianyu', Zhou Jiangqiao", Chen Zhongbao'"I, Ma Xiaoxiong'II', Zhang Long IV , Zou Jilin"v

'PhD, Department of Organ Transplantation, Renmin Hospital, Wuhan University, Hubei, China. Conception and design of the study, acquisition and analysis of data, manuscript writing.

"PhD, Department of Organ Transplantation, Renmin Hospital, Wuhan University, Hubei, China. Design and supervised all phases of the study.

'"Physician, Department of Organ Transplantation, Renmin Hospital, Wuhan University, Hubei, China. Technical procedures, acquisition of data.

"vphysician, Department of Organ Transplantation, Renmin Hospital, Wuhan University, Hubei, China. Manuscript preparation.

Abstract

Purpose: To investigate the long non-coding RNAs (IncRNAs) profile on renal ischemia reperfusion in a mouse model.

Methods: Microarray analysis was used to study the expression of misregulated IncRNA in a mouse model of renal ischemia reperfusion(I/R) with long ischemia time. Quantitative real-time PCR (qPCR) was used to verify the expression of selected IncRNAs and mRNAs.The potential functions of the IncRNA was analyzed by bioinformatics tools and databases.

Results: Kidney function was impaired in I/R group compared to the normal group. Analysis showed that a total of 2267 IncRNAs and 2341 messenger RNAs (mRNAs) were significantly expressed in I/R group ( $\geq 2$.0-fold, $p<0.05$ ). The qPCR result showed that IncRNAs and mRNAs expression were consistent with the microarray analysis. The co-expression network profile analysis based on five validated IncRNAs and 203 interacted mRNAs showed it existed a total of 208 nodes and 333 connections. The GO and KEEG pathway analysis results showed that multiple IncRNAs are involved the mechanism of I/R.

Conclusion: Multiple IncRNAs are involved in the mechanism of I/R.These analysis results will help us to further understand the mechanism of $\mathrm{I} / \mathrm{R}$ and promote the new methods targeted at IncRNA to improve I/R injury.

Key words: Kidney Transplantation. Ischemia. Reperfusion. RNA, Messenger. Mice. 


\section{- Introduction}

Occurrence of renal ischemiareperfusion (I/R) injury affects the outcome of kidney transplantation, which has a direct relationship with the survival of the recipient. The delayed graft function (DGF) rate of kidney transplantation from donation after cardiac death (DCD) reached up to $40-70 \%$ and was significantly higher than that from brain death donors and living donors ${ }^{1}$. The main factor responsible for this difference was the prolonged warm ischemic time ${ }^{2}$. The I/R injury mechanisms in DCD kidney transplantation are multifactorial and may include oxidative stress, mitochondrial $\mathrm{Ca}_{2}^{+}$overload, inflammation, cell apoptosis, necrosis, loss of cell polarity, dedifferentiation and proliferation of viable cells, and disruption of the generation of free radicals. Long non-coding RNAs (IncRNAs) are typically longer than 200 nucleotides. It has been demonstrated that IncRNAs exert comprehensive effects on biological processes, such as transcription, translation, splicing, and intracellular and extracellular trafficking, and are associated with numerous diseases ${ }^{3}$. IncRNAs can interact with proteins, DNAs, and RNAs and regulate gene expression at various levels, including epigenetic, transcriptional, and post-transcriptional regulation ${ }^{4}$. However, the possible role of IncRNAs in I/R injury has not received much attention.

Therefore, in this study, we used microarray analysis to analyze the IncRNA and mRNA expression differences in I/R model.The selected IncRNA and mRNA were verified by q-PCR. Gene Ontology $(\mathrm{GO})$ analysis and Kyoto Encyclopedia of Genes and Genomes (KEGG) analysis were performed to predict possible biological processes and potential signal pathways. In addition, co-expression network of IncRNA-mRNA was clarified by coding/noncoding gene co-expression (CNC) analysis.

\section{Methods}

\section{Animal preparation and experimental design}

The research project was approved by the research ethics committee (NSCF 81400753).

Male C57BL/6 mice (body weight 250300g) were obtained from the Experimental Animal Center of the Medical College of Wuhan University (Wuhan, China). The animals were maintained at the Central Animal Facility of Affiliated Renmin Hospital of Wuhan University according to standard guidelines, and experiments were conducted according to the guidelines of the Chinese Council for Animal Care. The mice were kept in an air-filtered, homoiothermal $\left(20-22^{\circ} \mathrm{C}\right)$, and light-controlled room (light from 7 a.m. to 7 p.m.) and allowed free access to a standard diet.

\section{Sample collection}

Mice were separated into two groups. Group 1: control group $(n=5)$, in which mice were subjected to a right nephrectomy but without the induction of a left renal ischemia, and Group 2:1/Rgroup $(n=5)$, in which mice were subjected to a right nephrectomy and left renal ischemia for $45 \mathrm{~min}$ followed by a reperfusion period of $24 \mathrm{~h}$. All mice were anesthetized with intraperitoneal pentobarbital $(50 \mathrm{mg} / \mathrm{kg})$ and were killed via decapitation. Mice were placed on an electric heating pad to maintain their body temperature at $37^{\circ} \mathrm{C}$. Their kidney tissues were removed and frozen in liquid nitrogen followed by storage at $-80^{\circ} \mathrm{C}$ prior to analysis.

Kidney function test and hematoxylin and eosin staining

After the 24-h reperfusion period, blood samples were collected from the inferior 
vena cava and centrifuged to determine the concentration of creatinine $(\mathrm{Cr})$. The $\mathrm{Cr}$ was measured in the blood using standard techniques with an Olympus AU 2700 Analyzer (Olympus Optical Co., Ltd., Tokyo, Japan).

After a $24 \mathrm{~h}$ reperfusion, the left kidney was excised. Then, the kidney tissue was fixed with $10 \%$ phosphate-buffered formalin, paraffin embedded, and sectioned to a thickness of $4 \mathrm{~mm}$ according to a standard procedure. Sections were deparaffinized and gradually hydrated before they were examined by hematoxylin and eosin (HE) staining. Morphological assessments were performed by an experienced renal pathologist who had not been informed of the experimental protocol.

\section{Microarray analysis}

Gene microarray analysis was performed on 5 pairs of kidney tissues from I/R group and normal group to detect differentially expressed IncRNA and mRNA. Approximately 35,923 IncRNAs and 24,881 coding transcripts were detected by the Arraystar Mouse LncRNA Microarray V3. The tissue preparations and microarray hybridization were performed using the Agilent Gene Expression Hybridization Kit (Agilent Technology Inc., USA). Then, the arrays were scanned using the Agilent Microarray Scanner and were finally analyzed using the Agilent Feature Extraction software. Differentially expressed transcripts were identified by foldchange screening at a threshold of $\geq 2$-fold and a $p$-value of $<0.05^{5}$. Pathway analysis was used to study the significant signaling pathways of the differentially expressed genes. GO analysis was used to explore the biological roles of the aberrantly expressed mRNAs, which included to three domains-molecular function, biological process, and cellular component.

\section{qRT-PCR validation}

The kidney tissue collected for IncRNA microarray analysis were used for quantitative real-time polymerase chain reaction (qRT$P C R$ ) validation.According to the instructions of the product, SuperScript III reverse transcriptase(Invitrogen, Grand Island, NY, USA) is used to reverse transcribe the total RNA into cDNA. The qRT-PCR was performed with the Applied Biosystems ViiA 7 RT PCR System and 2x PCR Master Mix. The PCR conditions consisted of: incubation at $95^{\circ} \mathrm{C}$ for $10 \mathrm{~min}$, followed by 40 cycles of $95^{\circ} \mathrm{C}$ for 10 $\mathrm{s}$ and $60^{\circ} \mathrm{C}$ for $1 \mathrm{~min}$. The relative expression levels of IncRNAs were calculated using the $2^{-\Delta \Delta C t}$ method and were normalized against $\beta$-actin. The primers for each gene are listed in Table 1. The data represent the means of three experiments. 
Table 1 - Primers designed for qRT-PCR validation of candidate IncRNAs and mRNAs.

\begin{tabular}{|c|c|c|c|}
\hline Name IncRNA/mRNA & Primer & $\operatorname{Tm}(\stackrel{\circ}{ })$ & Product length(bp) \\
\hline GAPDH(MOUSE) & $\begin{array}{l}\text { F:5' CACTGAGCAAGAGAGGCCCTAT3' } \\
\text { R:5' GCAGCGAACTTTATTGATGGTATT3' }\end{array}$ & 60 & 144 \\
\hline ENSMUST00000124572 & $\begin{array}{l}\text { F:5' GGTTAAAGCAACGGACAGAG 3' } \\
\text { R:5' TGGCAAAGTCCTTACCACAG 3' }\end{array}$ & 60 & 96 \\
\hline ENSMUST00000180989 & $\begin{array}{l}\text { F:5'AACCCGACAATGTAAGGACC3' } \\
\text { R:5' TGTAAAACCGCACAAGGCT3' }\end{array}$ & 60 & 200 \\
\hline ENSMUST00000147219 & $\begin{array}{l}\text { F:5'CCAGTTGAGGAGACAGGGAA3' } \\
\text { R:5' TGGCTAGAGCAGGGGATTA3' }\end{array}$ & 60 & 92 \\
\hline ENSMUST00000097928 & $\begin{array}{l}\text { F:5'TTGGAATGCCTTGGAGATG3' } \\
\text { R:5' GTTGGTTGTCACCGTTGCT 3' }\end{array}$ & 60 & 145 \\
\hline uc007mos.1 & $\begin{array}{l}\text { F:5'GCTGAGGCTTTGATGTTGC3' } \\
\text { R:5' TCCAGTTCTTGACGCTCTTCT 3' }\end{array}$ & 60 & 115 \\
\hline ENSMUST00000145410 & $\begin{array}{l}\mathrm{F}: 5^{\prime} \text { CTACCTGGACCCCAATACAAC3' } \\
\mathrm{R}: 5^{\prime} \text { ACCCAAGGCAAGTCACAAA3' }\end{array}$ & 60 & 181 \\
\hline NR_040589 & $\begin{array}{l}\text { F:5'GGACAGGATTTGGATTTCGA3' } \\
\text { R:5' TGACAGACCACCATAACAGACA3' }\end{array}$ & 60 & 184 \\
\hline ENSMUST00000139773 & $\begin{array}{l}\text { F:5'CAGTGCTCAAGAGACTCAGAAAA3' } \\
\text { R:5' AACAGGTGCTGGTCAAAGG3' }\end{array}$ & 60 & 259 \\
\hline ENSMUST00000169128 & $\begin{array}{l}\text { F:5' CCATCTAATGCCCTTTTCTG 3' } \\
\text { R:5' GCTTGTTCTGTATGTACTGGACC 3' }\end{array}$ & 60 & 150 \\
\hline NM_025684 & $\begin{array}{l}\text { F:5' CCTCCGAGACCTGAAACATC } 3^{\prime} \\
\text { R:5' CCCTCCAGTGCCTTGAAAT 3' }\end{array}$ & 60 & 279 \\
\hline AK078749 & $\begin{array}{l}\text { F:5' CGCTAATTCTTCCTCCGTG 3' } \\
\text { R:5' TGATTGGTCCGCACTTCTT 3' }\end{array}$ & 60 & 135 \\
\hline NM_028746 & $\begin{array}{l}\text { F:5' ACTCGGTGTCATTTCCCTCA 3' } \\
\text { R:5' TTCTTCAGCTCCCCTGCTAT 3' }\end{array}$ & 60 & 189 \\
\hline NM_013913 & $\begin{array}{l}\text { F:5' AACAGAGGCGAACATACAAGTG3' } \\
\text { R:5' CGTTGAAGTCCTGTGAGCCAT 3' }\end{array}$ & 60 & 139 \\
\hline NM_020013 & $\begin{array}{l}\text { F:5' GGAGGATGGAACAGTGGTAGGC3' } \\
\text { R:5' AGGCTTTGACACCCAGGATTTG3' }\end{array}$ & 60 & 104 \\
\hline NM_009114 & $\begin{array}{l}\text { F:5' ATACTGGGCTTACACTGCTCTTT3' } \\
\text { R:5' CTGTGCTTCCACCATTTGTC3' }\end{array}$ & 60 & 193 \\
\hline
\end{tabular}

GO annotations and KEGG analysis

We conducted a GO analysis to construct a meaningful annotation of genes and gene products. The ontology covers the domains of biological processes, cellular components, and molecular functions. The - $\log 10$ ( $p$-value) denotes enrichment score representing the significance of GO term enrichment among differentially expressed genes. Pathway analysis was performed to explore the significant pathways in differentially regulated gene profiles according to KEGG. Also, the $\log 10$ ( $p$-value) denotes an enrichment score showing the significance of the pathway correlations.

Construction of a co-expression network with GO and KEGG analysis

In order to identify the interaction between differentially expressed IncRNA and 
mRNA, we constructed the co-expression network with the verified IncRNA and related mRNA on the basis of correlation analysis. Cytoscape software was applied into construct the network between IncRNA and mRNA, while the pearson's correlation coefficients should not less that 0.992. In the figure of CNC, mRNAs were represented by a red node, while IncRNAs were represented by a green node.

\section{Statistical analyses}

Statistical analyses were performed using Graphpad Prism 5.0 (San Diego, CA, USA). Results were expressed as mean \pm standard error of the mean. The t-test was used to analyze the differences between the normal control and I/R group data in this study. Spearman's correlation analysis was used to detect the relationship between IncRNAs and mRNAs.A p-value of $<0.05$ and a fractional disappearance rate of $<0.05$ were used as thresholds to define markedly enriched GO terms/pathways.

\section{Results}

\section{Kidney function test and HE stain}

Compared with the normal control group, we observed increased levels of serum creatine in I/R group. HE staining of the kidney tissues showed that renal tubular cells in $I / R$ group presented I/R injury features, including tubular necrosis, renal tubular expansion, and renal tubular epithelial cellular microvilli disappearance (Fig. 1).

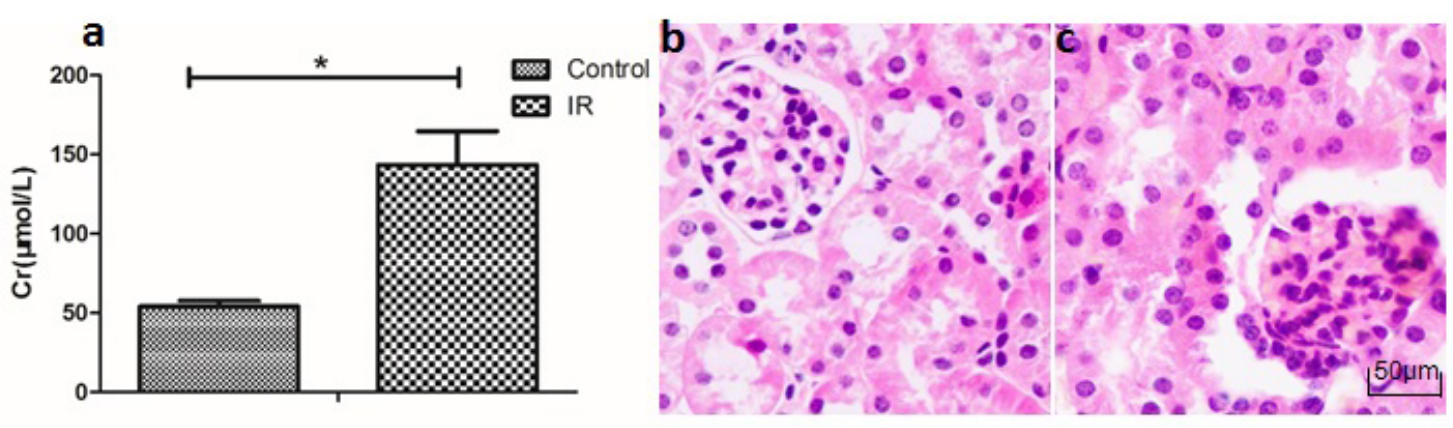

Figure 1 - Renal function was impaired in the I/R group when compared with the normal control group. a. The level of serum $\mathrm{Cr}$ is higher in the I/R group; “*” represents $\mathrm{p}<0.05$. b, c. HE staining in kidney tissue of the I/R (b) and control groups (c), showing I/R features in the tubular cells of the I/R group, including tubular necrosis, renal tubular expansion, and renal tubular epithelial cellular microvilli disappearance (magnification $\times 200)$.

IncRNA and mRNA expression analysis in renal $I / R$ injury

To explore the difference in the expression of IncRNA and mRNA in I/R model, microarray analysis was used to assess the expression levels. We identified 2267 significantly dysregulated IncRNAs in the $1 / R$ mice, while 1180 were upregulated, while 1087 were downregulated $(\geq 2.0$-fold, $p<0.05)$. Table 2 presents the 50 most significantly differentially expressed IncRNAs. 
Table 2 - Top 25 up and down expressed IncRNA in microarray analysis.

\begin{tabular}{|c|c|c|c|c|c|c|c|}
\hline Seq ID & $p$ value & Fold change & Regulation & Strand & Relationship & $\mathrm{Chr}$ & GeneSymbol \\
\hline NR_003548 & $2.35187 \mathrm{E}-08$ & 109.4887219 & up & + & intergenic & 3 & Sprr2g \\
\hline uc0̄07mos.1 & $.4733 E-09$ & 47.7396161 & up & - & exon sense-overlapping & 11 & Cyth1 \\
\hline humanlincRNA1590+ & 3.31079E-08 & 44.0254584 & up & + & intergenic & 5 & humanlincRNA1590 \\
\hline ENSMUST00000097928 & $1.94377 \mathrm{E}-06$ & 41.8941913 & up & + & natural antisense & 7 & Gm10574 \\
\hline ENSMUST00000147219 & $1.02731 \mathrm{E}-08$ & 39.3596471 & up & - & exon sense-overlapping & 2 & $\operatorname{Lcn} 2$ \\
\hline ENSMUST00000171867 & $1.41682 \mathrm{E}-07$ & 39.0995403 & up & - & intergenic & 14 & Gm9890 \\
\hline ENSMUST00000138796 & 1.00309E-08 & 35.7404452 & up & - & exon sense-overlap & 16 & BC100530 \\
\hline NR_073362 & 8.0896E-09 & 32.0782555 & up & - & intergenic & 14 & 1700091H14Rik \\
\hline ENS̄MUST00000167016 & $1.296 \mathrm{E}-10$ & 30.2506392 & up & - & intergenic & 14 & Gm17030 \\
\hline AK053244 & $1.19946 \mathrm{E}-05$ & 30.1399734 & up & - & intergenic & 13 & AK053244 \\
\hline ENSMUST00000163699 & $1.53946 \mathrm{E}-08$ & 29.9253704 & up & - & intergenic & 14 & Gm3719 \\
\hline AK078011 & $1.5941 \mathrm{E}-07$ & 29.2616428 & up & - & intergenic & 14 & AK078011 \\
\hline uc009oqw.1 & $6.091 \mathrm{E}-10$ & 27.1826111 & up & + & intronic antisense & 9 & AK077358 \\
\hline ENSMUST00000146254 & $3.28551 E-07$ & 25.6293449 & up & - & sense-overlap & 11 & Cd300If \\
\hline 00149944 & $1.63907 \mathrm{E}-04$ & 25.0 & up & + & exon sense-overlapping & 17 & Fpr2 \\
\hline TCO & $\mathrm{E}-08$ & 23. & up & - & nic & 4 & TCONS_0OC \\
\hline 22073 & 4.7 & 23. & up & - & enic & 4 & \\
\hline 49186 & $7 \mathrm{E}-$ & 22. & up & + & & 5 & \\
\hline AKC & $63 \mathrm{E}-06$ & 22. & up & + & & 3 & \\
\hline 27 & E-08 & 22. & up & + & nse- & 2 & \\
\hline 43 & 1.1 & 20. & up & - & & 14 & \\
\hline NR_C & $\mathrm{E}-07$ & 20. & up & - & inte & 11 & \\
\hline NR_C & 11 & 20.0 & up & - & nic & 13 & Rik \\
\hline T000001 & -10 & 19. & up & - & & 14 & \\
\hline 000146415 & $\mathrm{E}-08$ & 19.2 & up & - & nse-o & 4 & \\
\hline AK01 & $35 \mathrm{E}-08$ & 49319 & down & + & ectional & 1 & $\mathrm{AK}$ \\
\hline JST00000120915 & $1.29281 \mathrm{E}-07$ & 61.9993283 & down & - & genic & 3 & $\mathrm{Gn}$ \\
\hline uc009kit.1 & 2.20769E-08 & 54.6821234 & down & + & enic & 7 & $\mathrm{BC}$ \\
\hline 000121475 & $4.523 \mathrm{E}-10$ & 44.2610944 & down & - & enic & 3 & \\
\hline IUST00000132986 & $1.306 \mathrm{E}-10$ & 41.1148477 & down & - & & 11 & \\
\hline 0000120693 & 8.7904E-09 & 31.1 & down & - & & 3 & \\
\hline 0137279 & $6.623 \mathrm{E}-10$ & 29.4 & & + & sense-overlapping & 13 & \\
\hline & $\mathrm{E}-08$ & & down & + & & 14 & 80 \\
\hline 146 & -08 & & down & - & ng & 4 & $\mathrm{C} 8 \mathrm{a}$ \\
\hline 410 & -08 & 22. & down & + & antis & 9 & G \\
\hline & 6.3 & 19. & down & - & ic & 13 & $\mathrm{AK}$ \\
\hline 0000485 & 47E-07 & 18.6 & down & - & enic & 1 & XLOC_001255 \\
\hline $1395+$ & 13E-08 & 17. & down & + & enic & 7 & mouselinc \\
\hline 154598 & $1 \mathrm{E}-08$ & 17. & down & - & nse-overlapping & 2 & \\
\hline 00000131133 & 1.43599E-07 & 16.513081 & down & - & & 4 & \\
\hline ENSMUST00000155540 & $1.25951 \mathrm{E}-08$ & 16.2209832 & down & - & & 3 & $5730437 \mathrm{C1}$ \\
\hline uc007ana.1 & $1.23943 \mathrm{E}-07$ & 16.0098561 & down & + & & 1 & AK050085 \\
\hline ENSMUST00000133801 & 3.42096E-07 & 14.7898681 & down & + & nse-o & 7 & \\
\hline AKC & 4.7641E-09 & 14.3347262 & dov & - & antisense & 5 & $\mathrm{AK}$ \\
\hline cRNA2217- & $2.94943 E-07$ & 14.1063714 & down & - & & 4 & nlincRNA2217 \\
\hline 40589 & $6.761 \mathrm{E}-10$ & 13.8372003 & down & + & antisense & 3 & 6330410L21Rik \\
\hline NR_102276 & $9.9 \mathrm{E}-12$ & 13.2454412 & down & + & nic & 7 & $\mathrm{Al} 314278$ \\
\hline AA 189272 & $5.1804 \mathrm{E}$ & 8177 & down & + & enic & 2 & humanlincRNA1141 \\
\hline uc008yin.1 & 3.89772E-08 & 12.9396912 & down & + & intergenic & 5 & AK020506 \\
\hline ENSMUST0000014 & 8.3739E-08 & 12.8921193 & down & + & exon sense & 15 & Ugt3a2 \\
\hline
\end{tabular}

SeqID: IncRNA name. $P$ value:P value calculated from unpaired t-test. Fold Change: the absolute ratio (no log scale) of normalized intensities between two groups (IR vs Control). Chr: chromosome no. which IncRNA is transcribed. Strand: the strand of chromosome which IncRNA is transcribed; ' + ' is sense strand of chromosome, ' - ' is antisense strand of chromosome. Relationship: sense exon overlap^: the LncRNA's exon is overlapping a coding transcript exon on the same genomic strand; sense intron overlap^: the LncRNA is overlapping the intron of a coding transcript on the same genomic strand; antisense_exon_overlap ${ }^{\wedge}$ : the LncRNA is transcribed from the antisense strand and overlapping with a coding transcript; antisense_intron_overlap ${ }^{\wedge}$ : the LncRNA is transcribed from the antisense strand without sharing overlapping exons;" bidirection^: the LncRNA is oriented head to head to a coding transcript within 1000 bp; intergenic ${ }^{\wedge}$ : there are no coding transcripts within $30 \mathrm{~kb}$ of the LncRNA; others^: means other LncRNAs. GeneSymbol: IncRNA gene symbol.

Heat map and hierarchical clustering of the 50 most significantly differentially expressed IncRNAs expression patterns in different samples (Fig. 2a). All the variation in IncRNA expression between the I/R and normal control groups is shown using a scatter plot 
(Fig. 3a). At the same time, 2341 significantly dysregulated mRNAs were identified in the I/R group, while1166 were upregulated, while 1175 were downregulated ( $\geq 2.0$-fold, $p<0.05$ ). Table 3 presents the 50 most significantly differentially expressed mRNAs. Heat map and hierarchical clustering of the 50 most significantly differentially expressed mRNA expression patterns in different samples (Fig. $2 b)$. All the variation in mRNA expression between the I/R and control groups is shown using a scatter plot (Fig. 3b).

Table 3 - Top 25 up and down expressed mRNAs in microarray analysis.

\begin{tabular}{|c|c|c|c|c|c|c|}
\hline GeneSymbol & P-value & Fold Change & Regulation & seqname & strand & chrom \\
\hline Sprr2f & 1.9366E-09 & 1148.181643 & up & NM_011472 & + & chr3 \\
\hline 1700001F09Rik & $2.64 \mathrm{E}-11$ & 442.6745614 & up & NM_027940 & - & chr14 \\
\hline Sult1e1 & $1.26948 \mathrm{E}-06$ & 427.0273786 & up & NM_023135 & - & chr5 \\
\hline Krt20 & $1.1 \mathrm{E}-12$ & 425.3504883 & up & NM_023256 & - & chr11 \\
\hline Gm10377 & 7.795E-10 & 384.4778351 & up & NM_001244671 & - & chr14 \\
\hline Gjb4 & 3.63597E-06 & 255.815718 & up & NM_008127 & - & chr4 \\
\hline Gm10375 & 1.275E-10 & 135.8332007 & up & NM_001098269 & - & chr14 \\
\hline Lcn2 & $1.9 E-12$ & 87.6107745 & up & NM_008491 & - & $\operatorname{chr} 2$ \\
\hline Sprr2d & 1.62662E-05 & 81.1614053 & up & NM_011470 & + & chr3 \\
\hline Vgf & 5.89051E-06 & 74.1857763 & up & NM_001039385 & + & chr5 \\
\hline Gm5483 & 1.96007E-06 & 70.9697136 & up & NM_001082547 & + & chr16 \\
\hline BC061237 & 5.57972E-08 & 62.5468169 & up & NM_198677 & + & chr14 \\
\hline Ctxn3 & 8.5312E-09 & 60.5381104 & up & NM_001134697 & + & chr18 \\
\hline Chil3 & $2.73372 \mathrm{E}-07$ & 54.7387104 & up & NM_009892 & - & chr3 \\
\hline Stfa1 & 1.88196E-06 & 51.3837601 & up & NM_001082543 & + & chr16 \\
\hline Fgf21 & $1.228 \mathrm{E}-10$ & 49.9305516 & up & NM_020013 & - & chr7 \\
\hline Havcr1 & 3.4119E-09 & 45.0066413 & up & NM_001166631 & + & chr11 \\
\hline Orm2 & $2.40498 \mathrm{E}-08$ & 41.6527274 & up & NM_011016 & + & chr4 \\
\hline Ms4a8a & $6.13093 \mathrm{E}-05$ & 41.6072802 & up & NM_022430 & - & chr19 \\
\hline Krt12 & 7.77949E-07 & 37.0094785 & up & NM_010661 & - & chr11 \\
\hline Stfa2I1 & $1.56089 \mathrm{E}-06$ & 36.7724705 & up & NM_173869 & + & chr16 \\
\hline Havcr1 & 1.5051E-09 & 35.743044 & up & NM_134248 & + & chr11 \\
\hline $\mathrm{Cxcl} 2$ & 4.13451E-06 & 35.369706 & up & NM_009140 & + & $\operatorname{chr} 5$ \\
\hline Gm5416 & $1.8353 \mathrm{E}-04$ & 34.6385309 & up & NM_001082542 & + & chr16 \\
\hline$|v|$ & $2.12671 \mathrm{E}-04$ & 34.0747508 & up & NM_008412 & - & chr3 \\
\hline Car5a & $1.913 \mathrm{E}-10$ & 97.8555546 & down & NM_007608 & - & chr8 \\
\hline Slitrk6 & $3.88686 \mathrm{E}-07$ & 42.1200797 & down & NM_175499 & - & chr14 \\
\hline Pvalb & $6.27 E-11$ & 34.7214021 & down & NM_013645 & - & chr15 \\
\hline Slc7a13 & $1.36165 \mathrm{E}-08$ & 33.6931965 & down & NM_028746 & + & chr4 \\
\hline Angptl3 & $1.90038 \mathrm{E}-08$ & 29.4659423 & down & NM_013913 & + & chr4 \\
\hline Acmsd & 3.843E-10 & 28.087504 & down & NM_001033041 & + & chr1 \\
\hline Nccrp1 & 1.31903E-07 & 24.4742272 & down & NM_001081115 & - & chr7 \\
\hline Pappa2 & 2.19209E-07 & 23.125535 & down & NM_001085376 & - & chr1 \\
\hline Bhmt & $2.9 E-12$ & 21.4082897 & down & NM_016668 & - & chr13 \\
\hline Gys2 & $1.5504 \mathrm{E}-09$ & 21.171212 & down & NM_145572 & - & chr6 \\
\hline Gatm & $2.206 \mathrm{E}-10$ & 19.2441547 & down & NM_025961 & - & $\operatorname{chr} 2$ \\
\hline Egf & 1.5411E-09 & 18.9547528 & down & NM_010113 & - & chr3 \\
\hline Vmn1r19 & 3.176E-09 & 18.8127661 & down & NM_134182 & + & chr6 \\
\hline Unc13c & 4.3197E-06 & 18.5175514 & down & NM_001081153 & - & $\operatorname{chr} 9$ \\
\hline Hpd & 4.49995E-08 & 18.3616339 & down & NM_008277 & - & $\operatorname{chr} 5$ \\
\hline Nepn & 1.81913E-06 & 17.6920316 & down & NM_025684 & + & chr10 \\
\hline Slco4c1 & $3.77297 \mathrm{E}-06$ & 17.2959218 & down & NM_172658 & - & chr1 \\
\hline Ceacam 2 & $9.98525 \mathrm{E}-07$ & 17.2607985 & down & NM_001113369 & - & chr7 \\
\hline Mep1b & $6.6751 \mathrm{E}-09$ & 15.9869509 & down & NM_008586 & + & chr18 \\
\hline A4gnt & $2.49574 \mathrm{E}-08$ & 15.9408784 & down & NM_001077424 & + & chr9 \\
\hline Tmem207 & $1.41886 \mathrm{E}-06$ & 15.5512338 & down & NM_001101640 & - & chr16 \\
\hline Akr1c14 & $9.6481 \mathrm{E}-09$ & 15.0846971 & down & NM_134072 & + & chr13 \\
\hline Rdh7 & $5.5158 \mathrm{E}-08$ & 14.8091606 & down & NM_001150749 & - & chr10 \\
\hline Ugt2a3 & 9.93539E-06 & 14.5629187 & down & NM_028094 & - & $\operatorname{chr} 5$ \\
\hline Gm6878 & 1.9959E-04 & 14.4289555 & down & NM 001037931 & - & chr14 \\
\hline
\end{tabular}

GeneSymbol: mRNA gene symbol.P value:P value calculated from unpaired t-test. Fold Change: the absolute ratio (no log scale) of normalized intensities between two groups(IR vs Control). SeqID: mRNA name.Chr: chromosome no. which IncRNA is transcribed. Strand: the strand of chromosome which IncRNA is transcribed; ' + ' is sense strand of chromosome, ' - ' is antisense strand of chromosome. 

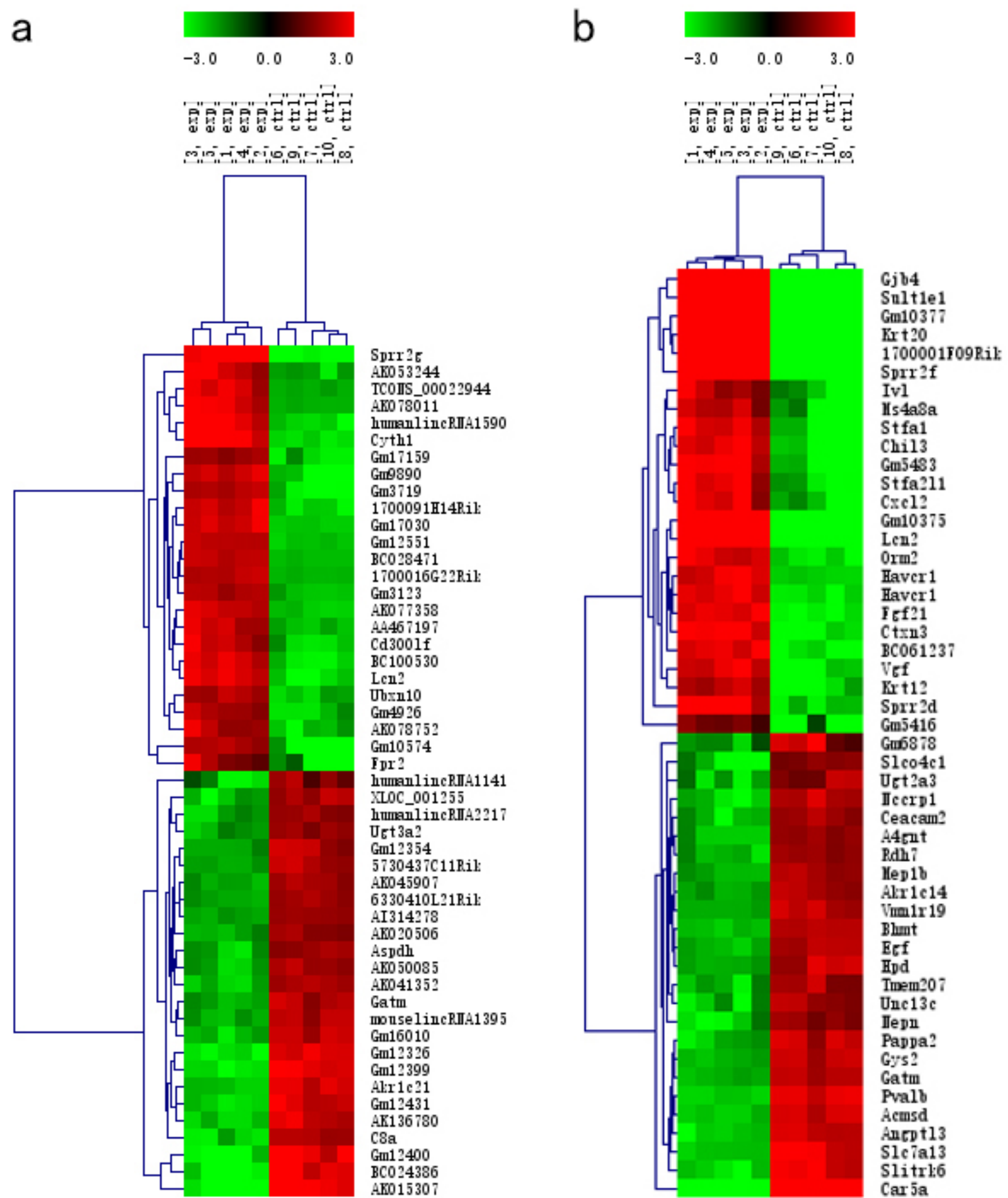

Figure 2 - Heat map and hierarchical clustering of the 50 most significantly differentially expressed IncRNAs (a) and mRNAs (b) between the I/R and control groups. The data are depicted as a data matrix, in which each row represents one IncRNA (mRNA) and each column represents one sample. The relative IncRNA (mRNA) expression follows the color scale at the top. Red represents high relative expression, and green represents low relative expression; $-3.0,0$, and 3.0 are fold changes in the corresponding spectrum. The magnitude of deviation from the median is represented by the color saturation. 
a
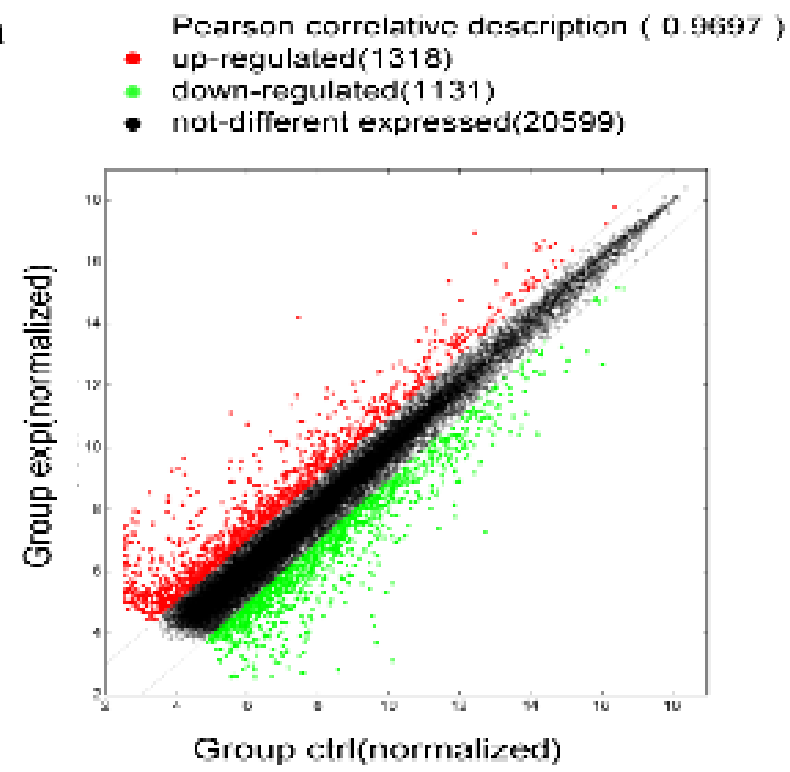

b Pearson correlative description ( 0.9624 )

- up-regulated(1250)

- down-regulated(1198)

- not-different expressed(17087)

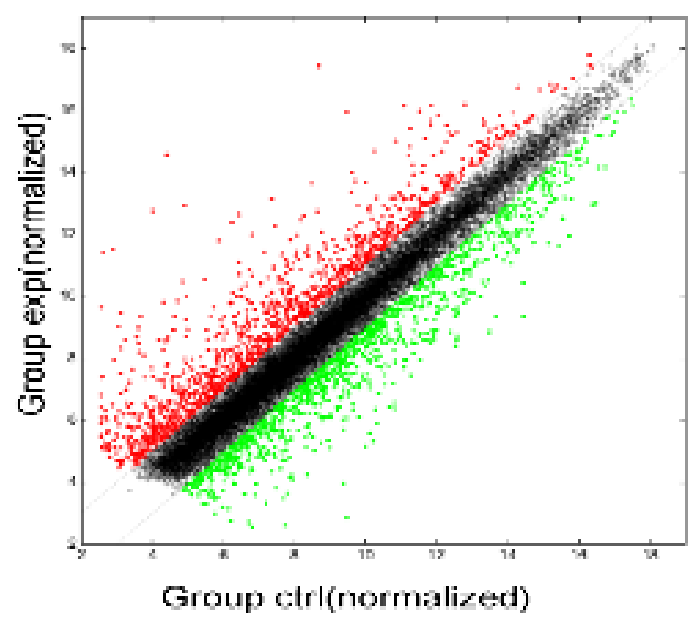

Figure 3 - Scatter plot of IncRNA (a) and mRNA (b) expression variation between the I/R and control kidney samples. The values shown on the $\mathrm{X}$-axis and $\mathrm{Y}$-axis are normalized signal values for each sample (log2 scale). The dark lines are fold-change lines (the default fold-change value given is 2.0 ). The green dot and red plots showed an expression fold-change of $>2.0$ between the two samples compared.

Validation of the microarray data using $q R T$ $P C R$

To validate the result of mRNA and IncRNA from microarray analysis, we performed the qRT-PCR assay.Ten mRNA and IncRNA were randomly selected to perform the qRT-PCR.The results showed that the expressions of IncRNA ENSMUST00000124572, ENSMUST00000180989, ENSMUST00000147219, ENSMUST00000097928, uc007mos1 and ENSMUST00000169128 were upregulated, whereas those of ENSMUST00000145410,
NR_040589, ENSMUST00000139773, and AK078749 were downregulated (Fig. 4). Meanwhile, when compared with the control group, three target mRNAs (NM_028746, NM_013913, and NM_025684)were found to be downregulated in the I/R group, whereas NM_020013 and NM_009114 were upregulated (Fig. 4). These results are consistent with those of the microarray analysis (Fig. 4), thereby confirming the validity of the microarray results. The finding provides compelling evidence that these IncRNAs and mRNAs could be implicated in the pathogenesis of renal I/R injury. 


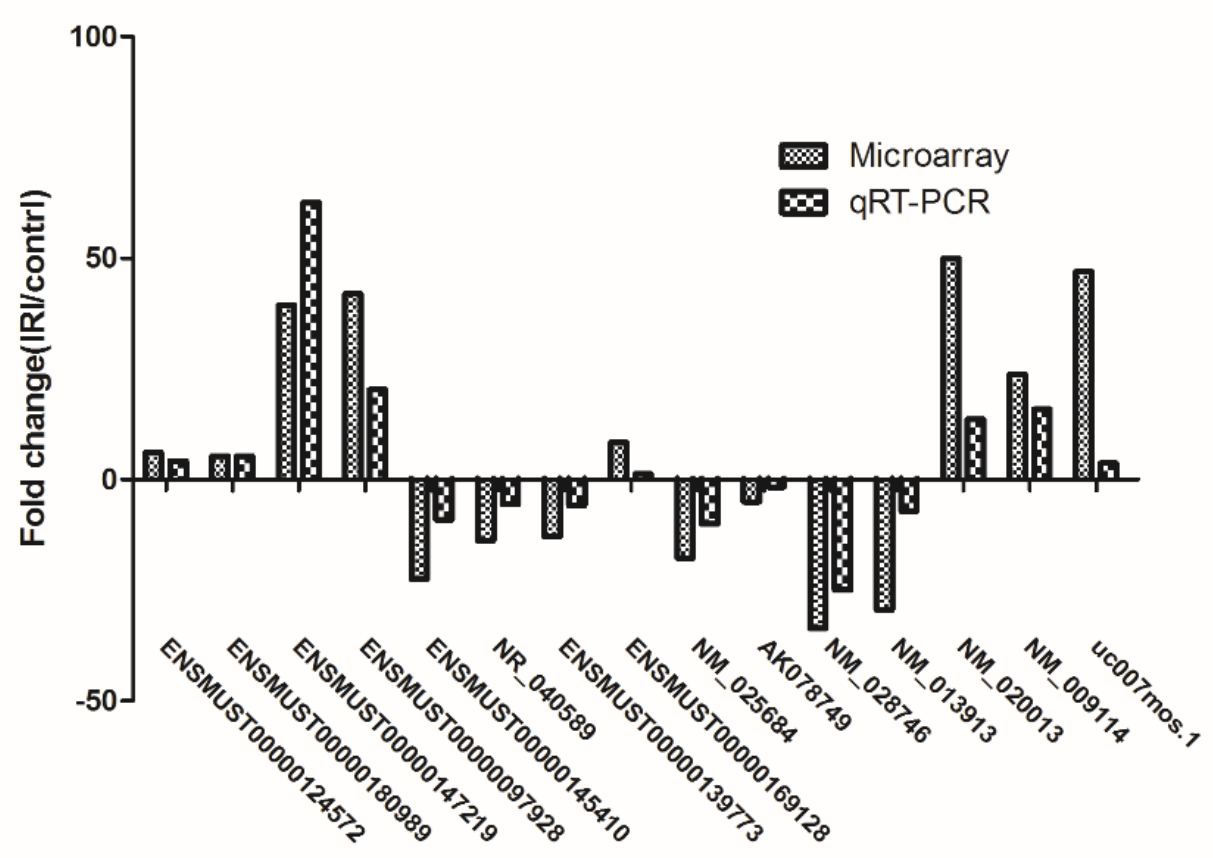

Figure 4 - The differential expression of IncRNAs and mRNAs was validated by quantitative real-time PCR (qRT-PCR). The data show that expression levels of IncRNAs ENSMUST00000145410, NR_040589, ENSMUST00000139773, NM_025684, and AK078749, along with mRNAs NM_028746 and NM_013913 were downregulated, while expression levels of IncRNAs ENSMUST00000124572, ENSMUST00000180989, ENSMUST00000147219, ENSMUST00000097928, ENSMUST00000169128, uc007 mos.1, and mRNAs NM_020013 and NM_009114 were upregulated in kidney tissue samples from I/R mouses when compared with the control mouses. The heights of the columns in the chart represent fold changes. The qRT-PCR results were consistent with the microarray data.

\section{GO analysis and KEGG pathway analysis}

The GO defines concepts/classes used to describe gene function, and relationships including three aspects molecular function, biological process and cellular component. In this study the GO term analysis indicates that the most enriched GO terms targeted by mRNAs co-expressed with IncRNAs were organic acid metabolic process (ontology: biological process, GO:006082), catalytic activity (ontology: molecular function, GO:0003824), and extracellular vesicular exosome (ontology: cellular component, GO:0070062) (Fig. 5). 


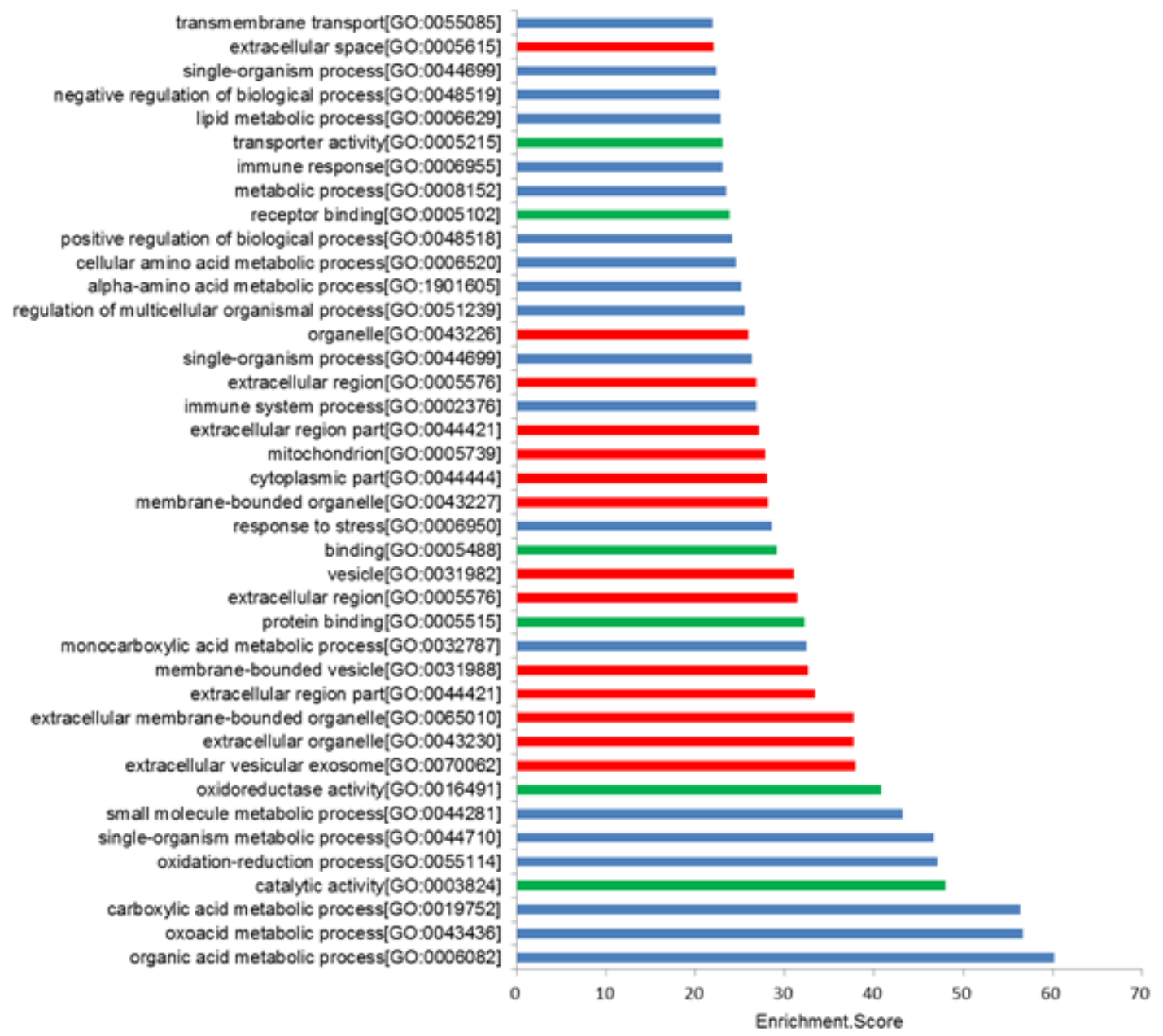

Figure 5 - The 40 most significant GO terms for differences in co-expressed IncRNA genes in I/R animals and controls. GO enrichment analysis provided a controlled vocabulary to describe co-expressed genes of differentially expressed IncRNAs. The ontology covered three domains: biological process (blue), cellular component (red), and molecular function (green).

Furthermore, we applied the KEGG tool to explore pathway maps on the molecular interaction, reaction and relation networks the results indicated that mRNAs co-expressed with IncRNAs were involved in the regulation of glycine, serine, and threonine metabolism;
TNF signaling pathway; AGE-RAGE signaling pathway in diabetic complications; cytokinecytokine receptor interaction; ECM-receptor interaction; $\mathrm{PI} 3 \mathrm{~K}-\mathrm{Akt}$ signaling pathway; and others. The 40 most significant KEGG pathways are listed in Figure 6. 


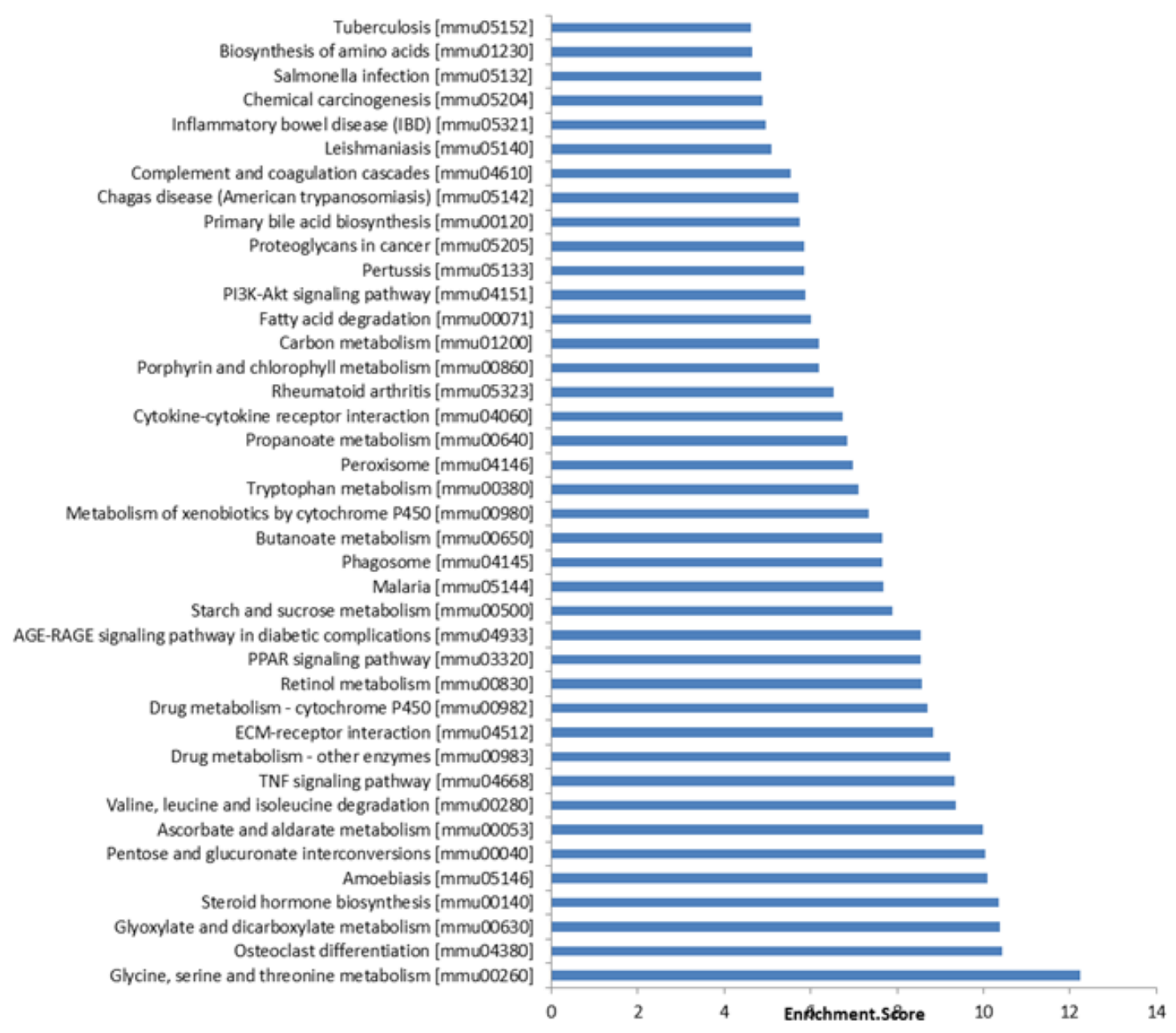

Figure 6 - The 40 most significant pathways for differences in IncRNA genes co-expressed in I/R injury animals and controls.

\section{IncRNA-mRNA CNC network analysis}

LncRNA is involved in the occurrence and development of $\mathrm{I} / \mathrm{R}$, but IncRNA mainly play functions by regulating the expression of mRNA, so we further analyzed the CNC network of IncRNA and mRNA. The 5 differentially expressed IncRNAs that were validated by qRTPCR (uc007 mos.1, ENSMUSTO0000147219, E N S M U S T 0000000124572 , ENSMUST00000145410, and NR_040589) with 203 interacting mRNAs were used to construct the co-expression network. This co-expression network was consisted of 208 nodes and 333 connections, of which 89 were negative and 244 were positive interactions. The resulting network revealed that uc007 mos.1 is correlated with 119 mRNAs, ENSMUST00000147219 is correlated with 54 mRNAs, ENSMUST00000124572 is correlated with 22 mRNAs, ENSMUST00000145410 is correlated with 81 mRNAs, and NR_040589 is correlated with 57 mRNAs (Fig. 7) . 


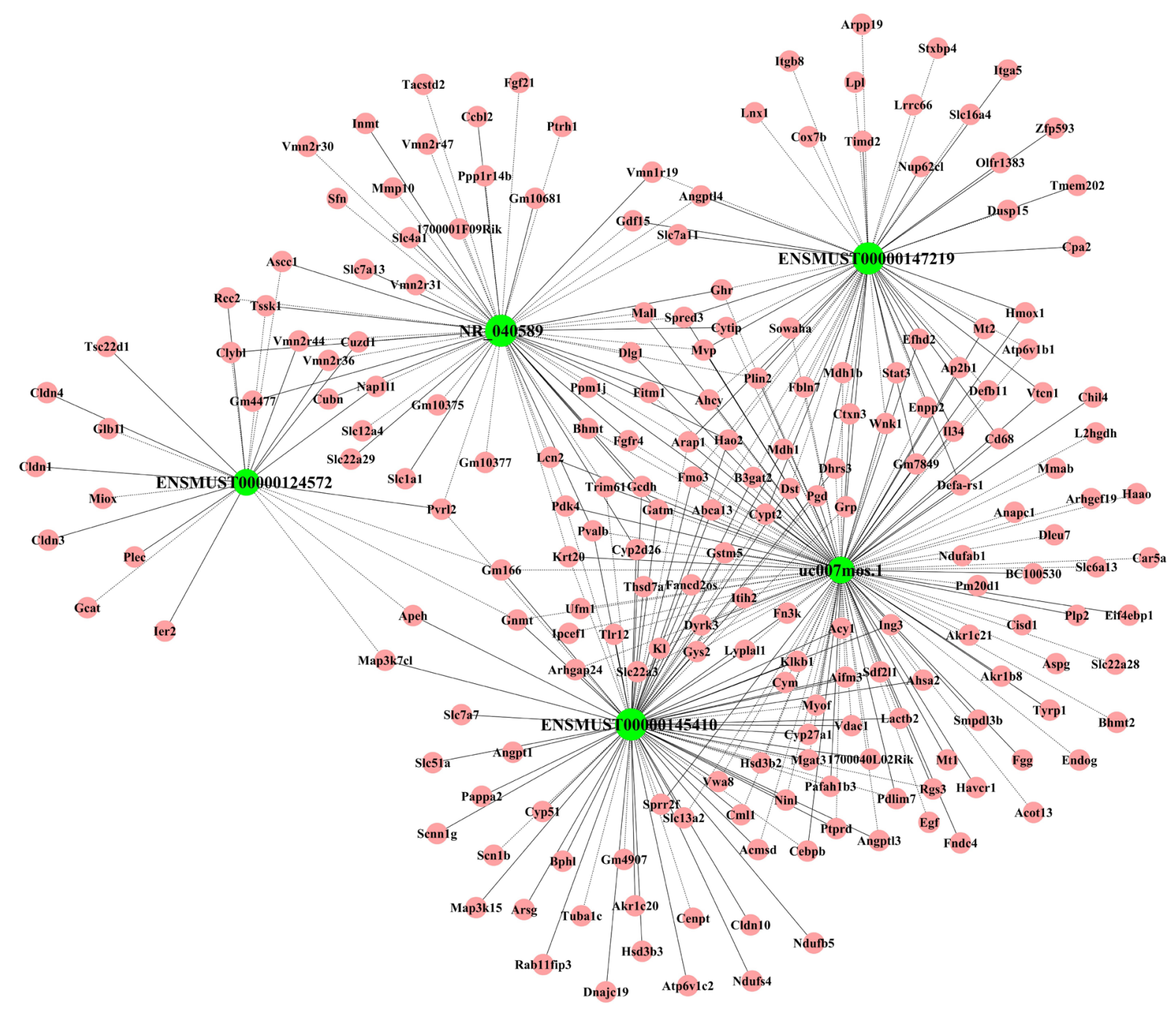

Figure 7 - IncRNA-mRNA network analysis. Green nodes represent dysregulated IncRNAs, whereas red nodes represent dysregulated mRNAs. The dotted lines between IncRNAs and mRNAs indicate a negative correlation, whereas solid lines indicate a positive correlation.

GO and KEGG analyses based on the results of the co-expression network were performed. According to the enrichment score level, the result showed that the targeted mRNA was focused on the organic acid metabolic process (ontology: biological process, GO:0004930), oxidoreductase activity (ontology: molecular function, GO:0016491), and extracellular exosome (ontology: cellular component, GO:0070062) (Fig. 8a).

In addition, most genes predicted by KEGG analysis were involved with glycine, serine, and threonine metabolism (pathway ID: mmu00260) (Fig. 8b). These results show that randomly selected IncRNA samples are very representative. 
a

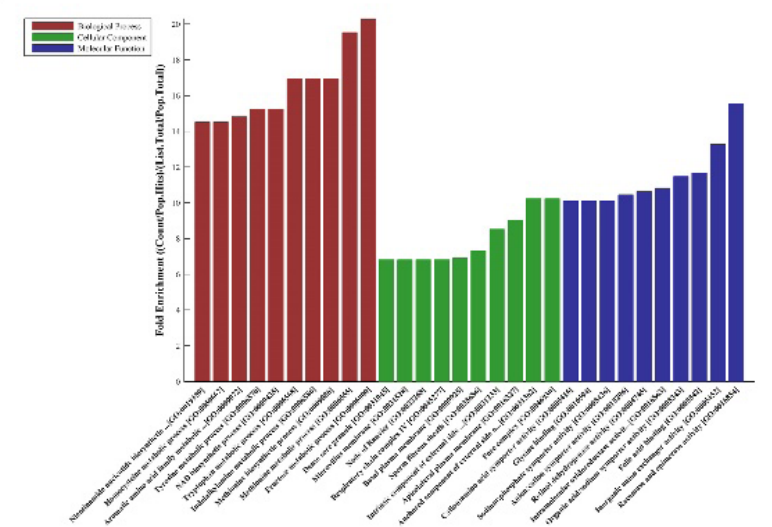

b

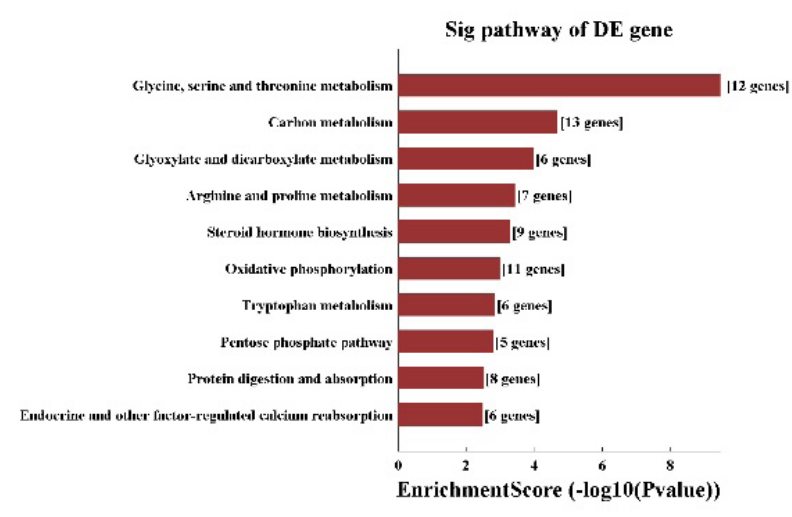

Figure 8 - GO analysis and pathway analysis with which targeted genes are correlated. a. According to the enrichment score levels, the results showed that mRNAs were enriched for organic acid metabolic process (ontology: biological process, GO: 0004930), oxidoreductase activity (ontology: molecular function, GO:0016491), and extracellular exosome (ontology: cellular component, GO:0070062). b. The result of KEGG pathway analysis with the targeted gene. Most of genes were predicted to interplay with glycine, serine, and threonine metabolism.

\section{- Discussion}

IncRNAs encompass a large and diverse class of transcribed RNA molecules that are longer than 200 nucleotides and do not encode proteins ${ }^{6}$. In recent years, more and more studies have shown that 1ncRNA participate in the occurrence and development of many diseases through a variety of mechanisms. IncRNAs contain complementary binding sites to micro RNAs (miRNAs) and serve as endogenous miRNA sponges, forming an IncRNA-miRNA axis to regulate cell processes, such as apoptosis, necrosis, and autophagy. IncRNAs can be categorized as sense, antisense, bidirectional, intronic, or intergenic, depending on their position with regard to protein coding genes ${ }^{7,8}$. LncRNAs interact with components of the cellular machinery, including protein, DNA, RNA and chromatin remodelling complexes, to regulate the expression of target genes.

Recent discoveries suggest that IncRNAs participate in renal processes and play pathogenic roles in kidney diseases ${ }^{9-11}$. Animal studies have linked IncRNAs to diabetic nephropathy, glomerular disease, acute renal allograft rejection, renal cell carcinoma, acute kidney injury, and hypertension. The regulation of IncRNAs expression will become novel targets for the treatment of kidney diseases ${ }^{4,6,12}$.

Although the role of non-coding RNA in renal ischemia reperfusion has been reported ${ }^{13}$, we tried to use a longer time model of thermal ischemia reperfusion (ischemia time $45 \mathrm{~min}$ ), which may lead to cell necrosis and inflammation and get the different resuls. We explored whole transcriptome profiles in a mouse model of I/R using microarray analysis and bioinformatics analysis. The results of serum creatine levels and $\mathrm{HE}$ pathological staining verified the reliability of the I/R model (Fig. 1). By microarray analysis, it has been identified 2267 significantly dysregulated IncRNAs in the I/R group, as well as 2341 significantly deregulated mRNAs in the $1 / R$ mouse (Figs. 2 and 3). These data provide the groundwork for a comprehensive analysis of potential IncRNAs involved in I/R.

Many studies have demonstrated that IncRNAs play an important role in AKI and 
other kidney diseases ${ }^{3,7,14}$. In the mouse model of renal I/R injury model, significant RANTES expression was observed in the renal tubular cells of wild type mice. RANTES-deficient mice showed improved renal function with reduced acute tubular necrosis, serum $\mathrm{Cr}$ levels, infiltration of inflammatory cells, and cytokine expression compared with the wild type mice ${ }^{15}$. The four specific target genes-ankyrin repeat and SOCS box 3, cation transport regulator homolog 2, peroxisomal membrane protein $11 \mathrm{~B}$, and trans-acting transcription factor 5 had been identified as being similarly associated with differentially expressed IncRNAs to regulate blood pressure and kidney disease ${ }^{16}$. In addition, we identified several of the dysregulated IncRNAs and mRNAs, based on qRT-PCR validation, and the results confirmed the microarray analysis findings to some extent (Fig. 4).

Recent studies have implicated IncRNAs can become potential biomarkers for related diseases in remodeling and dysfunction after $1 / R^{17}$. Thus, circulating or urinary IncRNAs may be fascinating novel biomarkers, which noninvasively reflect intra nuclear processes. And the IncRNA (e.g.AK139328 and IncRNAPRINS) in the pathogenesis of $I / R$ may therefore be markers of intracellular processes than currently established conventional biomarkers ${ }^{11,18}$. IncRNAs are strongly altered in the urine of patients with acute rejection, and urinary RP11-354P17.15-001 may serve as a novel biomarker of acute kidney rejection and predict loss of kidney function ${ }^{19}$. Plasma levels of circulating IncRNAs (TapSAKI, also known as MGAT3-AS1), could predict survival in patients with dialysis-dependent AKI. Arid2-IR is a novel IncRNA that functions to promote NF-KBdependent renal inflammation ${ }^{20,21}$. IncRNA-H19 expression was significantly upregulated in TGF- $\beta 2$-induced HK- 2 cell fibrosis and unilateral ureteral obstruction-induced renal fibrosis in vivo 22 .
Furthermore, to explore the potential functions of the differentially expressed IncRNAs identified in this study, GO and KEGG pathway analysis were performed using coding genes associated with significantly differentially expressed IncRNAs. GO analysis revealed that these IncRNAs are involved in biological processes such as organic acid metabolic process, catalytic activity, and extracellular vesicular exosome. KEGG pathway analysis indicated the enrichment of multiple pathways including glycine, serine, and threonine metabolism; cytokine-cytokine receptor interaction and $\mathrm{PI3K} / \mathrm{Akt}$ signaling pathway (Figs. 5 and 6). These results are consistent with previous studies of renal I/R. IncRNAs could serve as sponges to bind to miRNAs to regulate gene expression. The interactive networks of IncRNAs that regulate mRNAs reveal the important role of IncRNA function, which has biological significance ${ }^{23,24}$. The CNC network was performed to analyze the indicated IncRNA in this study, the result also showed these IncRNAs intersect multiple mRNAs and play multiple function in different pathways (Figs. 7 and 8). IncRNAs play multiple functions in different types of kidney cells, including renal tubular cells, endothelial cell, and podocytes. Long et al. ${ }^{6}$ reported that the IncRNA Tug1 contributes to CKD development. IncRNAs also exert the biological functions in many cellular components, such as the extracellular exosome, extracellular vesicle, and extracellular organelle $e^{7,25}$. All these suggest the great potential of IncRNA in the occurrence and development of renal diseases.

\section{- Conclusions}

IncRNA-mRNA expression was detected in the mouse model of kidney I/R by high-throughput microarray analysis. The expression profile showed that IncRNAs participate in several biological processes in 
renal I/R injury. Further research is needed to explore the potential role of IncRNAs in renal I/R injury.

\section{References}

1. Elgharably H, Shafii AE, Mason DP. Expanding the donor pool: donation after cardiac death. Thorac Surg Clin. 2015;25(1):35-46. doi: 10.1016/j.thorsurg.2014.09.011.

2. Morrissey PE, Monaco AP. Donation after circulatory death: current practices, ongoing challenges, and potential improvements. Transplantation. 2014;97(3):258-64. doi: 10.1097/01.TP.0000437178.48174.db.

3. Yu SY, Tang L, Zhou SH. Long noncoding RNAs: new players in ischaemia-reperfusion injury. Heart Lung Circ. 2018;27(3):322-32. doi: 10.1016/j.hlc.2017.09.011.

4. Wu X, Zhu H, Zhu S, Hao M, Li Q. IncRNA expression character associated with ischemic reperfusion injury. Mol Med Rep. 2017;16(4):3745-52. doi: 10.3892/ mmr.2017.7051.

5. Hanjin C, Tao L, Pengfei L, Ali $Y$, Huajun Z, Jiekun L, Yang W, Tao T. Altered long noncoding RNA and messenger RNA expression in experimental intracerebral hemorrhage - a preliminary study. Cell Physiol Biochem. 2018;45(3):1284-301. doi: $10.1159 / 000487464$.

6. Li SY, Susztak K. The long noncoding RNA Tug1 connects metabolic changes with kidney disease in podocytes. J Clin Invest. 2016;126(11):4072-5. doi: 10.1172/ JCl90828.

7. Batista PJ, Chang HY. Long noncoding RNAs: cellular address codes in development and disease. Cell. 2013;152(6):1298-307. doi: 10.1016/j.cell.2013.02.012.

8. Yang $B$, Xia ZA, Zhong $B$, Xiong $X$, Sheng C, Wang Y, Gong W, Cao Y, Wang Z, Peng W. Distinct hippocampal expression profiles of long non-coding RNAs in an Alzheimer's disease model. Mol Neurobiol. 2017;54(7):4833-46. doi: 10.1007/s12035016-0038-5.

9. Jiang $X$, Lei $R$, Ning $Q$. Circulating long noncoding RNAs as novel biomarkers of human diseases. Biomark Med. 2016;10(7):757-69. doi: $10.2217 / \mathrm{bmm}$ 2016-0039.
10.Wilflingseder J, Reindl-Schwaighofer R, Sunzenauer J, Kainz A, Heinzel A, Mayer $B$, Oberbauer R. MicroRNAs in kidney transplantation. Nephrol Dial Transplant. 2015;30(6):910-7. doi: 10.1093/ndt/gfu280.

11.Zhou P, Chen Z, Zou Y, Wan X. Roles of noncoding RNAs in acute kidney injury. Kidney Blood Press Res. 2016;41(6):757-69. doi: 10.1159/000450566.

12. Richards EJ, Zhang G, Li ZP, Permuth-Wey J, Challa S, Li Y, Kong W, Dan S, Bui MM, Coppola D, Mao WM, Sellers TA, Cheng JQ. Long non-coding RNAs (LncRNA) regulated by transforming growth factor (TGF) $\beta$. LncRNAHIT-mediated TGF-induced epithelial to mesenchymal transition in mammary epithelia. J Biol Chem. 2016;291(43):22860. doi: 10.1074/jbc.A114.610915.

13.Jun Zhou, Hongtao Chen and Youling Fan. Systematic analysis of the expression profile of non-coding RNAs involved in ischemia/ reperfusion-induced acute kidney injury in mice using RNA sequencing. Oncotarget. 2017;8,(59):100196-215. doi: 10.18632/ oncotarget.22130.

14.Lin J, Zhang $X$, Xue C, Zhang $H$, Shashaty MG, Gosai SJ, Meyer N, Grazioli A, Hinkle C, Caughey J, Li W, Susztak K, Gregory BD, Li M, Reilly MP. The long noncoding RNA landscape in hypoxic and inflammatory renal epithelial injury. Am J Physiol Renal Physiol. 2015;309(11):F901-13. doi: 10.1152/ ajprenal.00290.2015.

15. Yu TM, Palanisamy K, Sun KT, Day YJ, Shu $\mathrm{KH}$, Wang IK, Shyu WC, Chen P, Chen YL, Li CY. RANTES mediates kidney ischemia reperfusion injury through a possible role of HIF-1 $\alpha$ and LncRNA PRINS. Sci Rep. 2016;6:18424. doi: 10.1038/srep18424.

16.Lorenzen JM, Thum T. Long noncoding RNAs in kidney and cardiovascular diseases. Nat Rev Nephrol. 2016;12(6):360-73. doi: 10.1038/nrneph.2016.51.

17.Lorenzen JM, Schauerte C, Kölling $M$, Hübner A, Knapp M, Haller H, Thum T. Long noncoding RNAs in urine are detectable and may enable early detection of acute T cellmediated rejection of renal allografts. Clin Chem. 2015;61(12):1505-14. doi: 10.1373/ clinchem.2015.243600.

18. Huang YS, Hsieh HY, Shih HM, Sytwu HK, Wu CC. Urinary Xist is a potential biomarker for membranous nephropathy. Biochem 
Biophys Res Commun. 2014;452(3):415-21. doi: 10.1016/j.bbrc.2014.08.077.

19.Chen W, Peng W, Huang J, Yu X, Tan K, Chen $Y$, Lin X, Chen D, Dai Y. Microarray analysis of long non-coding RNA expression in human acute rejection biopsy samples following renal transplantation. Mol Med Rep. 2014;10(4):2210-6. doi: 10.3892/ mmr.2014.2420.

20.Lorenzen JM, Schauerte C, Kielstein JT, Hübner A, Martino F, Fiedler J, Gupta SK, Faulhaber-Walter R, Kumarswamy R, Hafer C, Haller $\mathrm{H}$, Fliser $\mathrm{D}$, Thum T. Circulating long noncoding RNATapSaki is a predictor of mortality in critically ill patients with acute kidney injury. Clin Chem. 2015;61(1):191201. doi: 10.1373/clinchem.2014.230359.

21.Zhou Q, Huang XR, Yu J, Lan HY. Long noncoding RNA Arid2-IR is a novel therapeutic target for renal inflammation. Mol Ther. 2015;23(6):1034-43. doi: 10.1038/ mt.2015.31.
22.Xie $H$, Xue JD, Chao F, Jin YF, Fu Q. Long non-coding RNA-H19 antagonism protects against renal fibrosis. Oncotarget. 2016;7(32):51473-81. doi: 10.18632/ oncotarget.10444.

23. Mercer TR, Dinger ME, Mattick JS. Long noncoding RNAs: insights into functions. Nat Rev Genet. 2009;10(3):155-9. doi: 10.1038/ nrg2521.

24.Shi $X$, Sun $M$, Liu $H$, Yao $Y$, Song Y. Long non-coding RNAs: a new frontier in the study of human diseases. Cancer Lett. 2013;339(2):159-66. doi: 10.1016/j. canlet.2013.06.013.

25. Carpenter S, Aiello D, Atianand MK, Ricci EP, Gandhi P, Hall LL, Byron M, Monks B, Henry-Bezy $M$, Lawrence JB, O'Neill LA, Moore MJ, Caffrey DR, Fitzgerald KA. A long noncoding RNA mediates both activation and repression of immune response genes. Science. 2013;341(6147):789-92. doi: $10.1126 /$ science. 1240925.

\section{Correspondence:}

Zhou Jiangqiao

Department of Organ Transplantation, Renmin

Hospital

Wuhan University

ZiYang Road 99\#, Wuhan 430060 China

Phone: 86-27-88041911-82235

zhoujq@whu.edu.cn

Received: Dec 12, 2018

Review: Feb 08, 2019

Accepted: Mar 13, 2019
Conflict of interest: none

Financial source: National Natural Science Foundation of China (No. 81400753) 